\title{
Disaster Planning: Important Papers and Documents ${ }^{1}$
}

Josephine Turner ${ }^{2}$

\section{Overview}

Disasters are a part of life. Whether the disaster is a hurricane, tornado or a terrorist attack preparation is the key to survival and to clean up after the event. Knowing where your family's records and valuable documents are and being able to pick them up and take them with you, if you must evacuate, can save valuable time. For your "on the go" papers you will want to purchase a packet, folder, brief case or other carrying case for your documents. Place documents in this case in a secure but easily accessed location in your home. Then if you need to evacuate, important documents that need to go with you are in one place.

If you have access to scanner, you may want to scan your papers, documents, and photographs to a computer disk and keep the copy in the carrying case and leave the original in the recommended storage place. You may also want to videotape the contents of your home to supplement your household inventory. If you use a software package to keep track of your finances keep a back-up copy with your "on the go" papers and monthly update the back-up disk.

\section{"On the go" Important Papers and Documents Checklist}

Important papers are papers or documents that you will need sometime during your lifetime for a variety of reasons, such as a birth certificate is used for proof of age and or citizenship to obtain a drivers license or to go on a cruise. Other important papers include adoption, marriage and death certificates, passports, deeds, leases, insurance policies, social security records, contracts, wills, trusts and ownership papers.

\section{Why should you be concerned about important papers?}

In case of a disaster, it would be difficult to remember or identify exactly what you lost. Valuable time and money could be lost while you try to remember what possessions you owned or replace lost documents. Therefore it is much better to protect valuable papers than to replace them.

\section{Papers to keep on your person (wallet or purse):}

- Personal identification: name, address, telephone number and name, address and telephone number of a relative or close friend.

- Credit Cards

- Medical Information: blood type, diseases (diabetes, heart disease, epilepsy, etc.)

- Doctor's name, address and telephone number

1. This document is FCS9197, one of a series of the Department of Family, Youth and Community Sciences, Florida Cooperative Extension Service, IFAS, University of Florida, Gainesville FL 32611. First published: May 2003. Reviewed by Elizabeth Bolton, Ph.D., Department of Family, Youth and Community Sciences. Please visit the EDIS Web site at http://edis.ifas.ufl.edu

2. Josephine Turner, Ph.D., professor, Department of Family, Youth and Community Sciences, University of Florida, Gainesville FL 32611. 
- Social Security Card

- Ready cash for emergencies

- Driver's license

\section{"On the go papers" filed in special packet}

Disk of family records including the following or a copy of the following:

- Checking Account numbers and bank

- List of savings and investments including CDs, stocks, bonds, and mutual funds

- Credit card safety record

- Household inventory - videotape, paper copy, and or disk

- List of Insurance policies with name of company, type of policy and policy number

- Copy of will and trust documents

- Titles (house, car, other property)

- Certificates or a copy of them: birth, marriage, divorce, death, and adoption

- Passports

- List of family advisors: accountant, attorney, banker, doctors, dentist, employer, financial adviser, Insurance agents, religious leader, banker,

- Bank account numbers

- Educational records

- Investment record

- Military records

- Debt Instruments

- Other special papers that would be difficult or impossible to replace if lost.

$\bullet$ 